\title{
La production officielle des différences culturelles
}

Introduction

Narguesse Keyhani et Sylvain Laurens

\section{CpenEdition}

Journals

Édition électronique

URL : http://journals.openedition.org/conflits/19525

DOI : $10.4000 /$ conflits. 19525

ISSN : $1777-5345$

Éditeur :

CCLS - Centre d'études sur les conflits lilberté et sécurité, L'Harmattan

Édition imprimée

Date de publication : 30 octobre 2017

Pagination : 9-13

ISBN : 978-2-343-13540-3

ISSN : 1157-996X

Référence électronique

Narguesse Keyhani et Sylvain Laurens, "La production officielle des différences culturelles », Cultures

\& Conflits [En ligne], 107 | automne 2017, mis en ligne le 30 octobre 2017, consulté le 30 mars 2021.

URL : http://journals.openedition.org/conflits/19525; DOI : https://doi.org/10.4000/conflits. 19525 


\section{La production officielle des différences culturelles}

Introduction

\section{Narguesse KEYHANI, Sylvain LAURENS}

Narguesse Keyhani est post-doctorante à l'ISP où elle participe à une enquête collective sur le traitement judiciaire des infractions racistes (JUSTIRACE / GIPJustice). Ses enquêtes (doctorale et en cours) portent sur la sociologie de l'action publique et les mobilisations contre le racisme et les discriminations.

Sylvain Laurens est maître de conférences à l'EHESS et chercheur au CESSP. Il est notamment l'auteur de l'ouvrage Une politisation feutrée. Hauts fonctionnaires et immigration en France (2009). Ses travaux se situent au croisement de la socio-histoire de l'État et des classes dominantes.

$\mathrm{F}$ n prenant pour objet la fabrique des discours sur les modes de vie, les rapports entre groupes ethnicisés et le reste de la population ou sur les pratiques déviantes de descendants d'immigrés, ce dossier s'intéresse aux «cultures » des immigrés et des populations colonisées. Mais il se concentre sur ceux qui les produisent, poursuivant en cela des travaux ayant mis en lumière le classement hiérarchisé des pratiques culturelles par les agents de l’État ${ }^{1}$. Ce dossier s'intéresse aux acteurs qui formulent des discours sur certaines pratiques culturelles perçues comme "différentes ", en appellent à les reconnaître, les promouvoir ou au contraire à les « adapter » ou les transformer. Il vise à rendre intelligible ce travail en identifiant des configurations socio-historiques qui le rendent possibles.

Les articles proposent un éclairage sur différentes périodes de l'histoire des discours sur l'immigration, les immigrés et sur les populations coloniales. Couvrant une période qui s'étend des années 1960 aux années 2010, ils offrent un panorama de configurations ayant produit de tels discours. Les moments de redéfinition ou de transformation partielle des politiques publiques favorisent l'émergence d'une production symbolique officielle sur ce qui est censé

1. Sayad A., Les Usages sociaux de la culture des immigrés, Paris, CIEMM, 1978. 
constituer la «culture » de ces populations. Les articles reviennent ainsi sur la production de savoirs et d'analyses et sur leur mobilisation dans l'action publique à la faveur des transformations des rapports entre les pouvoirs publics et les colonies ou ex-colonies, la mise en place d'une politique d'immigration plus restrictive, l'institutionnalisation locale d'une politique mémorielle, d'une action policière préventive ou encore la réforme des programmes scolaires.

Mobilisant des approches aussi diverses que la sociologie de l'action publique, des mobilisations, de l'institutionnalisation, de la police, la sociohistoire du travail bureaucratique ou encore des savoirs et de l'expertise, les contributions mettent en lumière ce qui, dans ces configurations précises, favorise cette production symbolique à travers l'analyse du rôle d'une grande variété d'acteurs (agents administratifs et préfectoraux, hauts fonctionnaires, élus locaux, policiers, acteurs associatifs, chercheurs...) amenés à produire des catégories de classement désignant par exemple ce qui distinguerait les travailleurs immigrés des travailleurs français en termes de modes de vie, de rapport à la famille, à l'habitat ou à l'espace. En fonction des acteurs qui les portent, ces discours ne se focalisent pas uniquement sur les immigrés. Ils peuvent aussi prendre pour objet, dans une perspective critique, le traitement de ces populations par les institutions appréhendées par exemple à travers l'enseignement de l'histoire dans l'éducation nationale ou la mémoire d'une commune.

Ce dossier place au centre de sa problématique le fait qu'érigées de longue date en problème par les pouvoirs publics, notamment par l'administration, les «cultures » des immigrés et de leurs descendants font l'objet de nombreux discours descriptifs et prescriptifs qui contribuent à l'altérisation de certaines franges des classes populaires. Le processus est ancien mais le développement des migrations en provenance des colonies puis, à partir des années 1960, des anciennes colonies françaises a constitué le terreau privilégié pour le développement de discours administratifs et politiques sur les effets «nocifs» de cette immigration sur le territoire français, en raison d'une altérité culturelle jugée inédite par rapport aux migrations européennes. Les contributions réunies ici entendent replacer au cour de l'analyse la production symbolique en la matière, opérée par les agents administratifs. Elles soulèvent ainsi un point aveugle d'une certaine littérature sociologique qui discute la question des différences culturelles sans prendre en compte l'inégale distribution des capacités de classement des agents sociaux.

Car les sciences sociales ne sont pas restées en marge de ces débats. De la sociologie de la déviance à celle du genre, en passant par celle de la famille, la culture des immigrés fait l'objet de nombreuses enquêtes. Certains travaux en font un facteur d'explication des phénomènes observés, et notamment des formes de déviance, en reprenant souvent l'idée d'une « distance culturelle 2 » 
entre les immigrés et leurs descendants d'une part et le reste de la société d'autre part. D'autres travaux encore plus récents ont insisté sur l'idée d'une « insécurité culturelle ${ }^{3}$ » dont serait victime en retour une partie des classes populaires «françaises » peu intégrées à l'État-nation. Ces prises de position font écho à des discours administratifs bien connus des historiens et sociologues des politiques d'immigration et d'insertion ${ }^{4}$. Ces travaux ont fait l'objet de nombreuses critiques savantes, pointant notamment le rôle prêté aux cultures dans l'entre-soi familial, un facteur susceptible d'éclairer uniquement les pratiques des descendants d'immigrés ${ }^{5}$. Outre cet usage controversé de la " culture », cette notion tient également une place centrale dans les postcolonial studies telles qu'elles se sont développées en France dans les années 2000 avec une ambition critique manifeste. Celle-ci s'incarne à travers l'appel à considérer la domination coloniale dans toutes ses dimensions (politique, économique, mais aussi culturelle) et par le postulat d'une perpétuation des formes de cette domination, malgré les décolonisations officielles, dans les sociétés décolonisées comme dans les anciennes sociétés colonisatrices. Ces travaux ont largement été commentés, parfois de façon virulente, à partir d'une relativisation de la nouveauté du questionnement sur les permanences des modes de domination coloniale dans la société française et de la surdétermination accordée à la domination coloniale pour expliquer les sociétés contemporaines ${ }^{6}$. Ils ont également été critiqués en raison de la focalisation sur les identités et cultures et leur réification ou encore pour la place centrale que tient dans ce champ d'études l'analyse textuelle et sémantique du « discours colonial ", oubliant l'analyse de sa réception et de ses usages ${ }^{7}$. Ces critiques invitent justement à interroger les processus de domination, notamment culturelles, en privilégiant les enquêtes sur les conditions pratiques de possibilité d'un « legs colonial » après les décolonisations, sans pour autant y réduire les logiques de production de discours sur les cultures.

À travers les cas étudiés, les contributions réunies dans ce numéro mettent en évidence plusieurs dimensions de la fabrique officielle de discours sur l'immigration et les immigrés : leur émergence s'accompagne d'un travail de persuasion de l'existence d'un besoin de connaissances et de savoirs sur l'«identité » de ces populations. Elle dérive de la nécessité pour les locuteurs de ces discours de justifier leur action ou leur position dans un champ. Observés depuis des organisations (Commission nationale pour les Études des Relations interethniques, Office national de promotion culturelle des immigrés), les champs dans lesquels ils sont mobilisés (champs académique, poli-

2. Lagrange H., Le déni des cultures, Paris, Seuil, 2010.

3. Bouvet L., L'insécurité culturelle, Paris, Fayard, 2015.

4. Rudder V., "La tolérance s'arrête au seuil », Pluriel, n² 21, 1980, pp. 3-13.

5. Mohammed M. et M. Selz, "Le déni des familles ? ", Sociologie, 2011, https://sociologie.revues.org/896.

6. Bayart J.-F., Les études postcoloniales : un carnaval académique, Paris, Khartala, 2010.

7. Sibeud E., «Post-Colonial et Colonial Studies: enjeux et débats », Revue d'histoire moderne et contemporaine, vol. 5, $\mathrm{n}^{\circ}$ 51-4 bis, 2004, pp. 87-95. 
tique...) ou encore à travers l'analyse de routines professionnelles, ces discours sur les cultures montrent comment le travail de catégorisation des individus dans des groupes sociaux définis par des attributs culturels répond à des logiques autres que le seul travail de description des populations ciblées.

Sylvain Laurens revient sur le travail de l'Office national de promotion culturelle des immigrés créé par le secrétariat d'État aux travailleurs immigrés (SETI) en 1976 et en fait une entrée pour observer les modes d'inculcation d'une pensée d'État. Alors que se met en place la nouvelle politique d'immigration et en particulier la politique des retours, il montre comment le travail d'information des Français sur les « coutumes » des travailleurs immigrés et en direction des travailleurs saisonniers s'articule avec les politiques du secrétariat d'État. La «promotion culturelle » des travailleurs immigrés répond à la volonté du SETI de séduire l'électorat de gauche tout en entretenant les liens des travailleurs immigrés avec les «cultures » des pays d'émigration.

L'article de Narguesse Keyhani s'intéresse au rôle de hauts fonctionnaires dans la création en 1966 de la Commission nationale pour les Études des Relations interethniques. Leur socialisation dans les institutions onusiennes qui formulent dès les années 1950 les termes de la «question des races » et leur investissement dans la politique nationale de coopération scientifique dans le contexte des décolonisations éclairent l'élaboration d'un besoin de savoirs sur les « relations interethniques » et les orientations pratiques qui leur sont attribuées. L'article permet de comprendre comment émerge une interface organisée entre administration et chercheurs qui favorise une nouvelle lecture de la question immigrée en plaçant les cultures des travailleurs immigrés au cœur d'un programme de recherche.

Jérémie Gauthier s’intéresse quant à lui à la place que tiennent les discours sur les cultures des immigrés dans l'action policière à Berlin. L'examinant à travers les politiques publiques de sécurité, les représentations professionnelles et les pratiques policières sur le terrain, il identifie une culturalisation de l'action policière préventive au sein de la police berlinoise. À la différence de répertoires d'action policiers répressifs, la police berlinoise fonde sa légitimité sur la constitution de "réseaux » avec des acteurs extérieurs à l'institution (mairies, écoles, associations, travail social) et en mobilisant des « compétences interculturelles ». Si cette stratégie préventive a pour effet de redéfinir le rôle traditionnel de la police au sein de la démocratie locale, elle peut conduire à des formes de «profilage culturel ».

Déplaçant l'observation des cultures des immigrés à celles de la visibilité de leur histoire dans le patrimoine, l'article de Victor Collet revient sur une mobilisation des années 2000 pour la reconnaissance de la mémoire de la colonisation et de l'immigration dans une municipalité de gauche. Il montre com- 
ment la rencontre entre le renouvellement du conseil municipal et l'ascension de militants associatifs accélère l'institutionnalisation de la mémoire comme l'illustrent les débats pour une école au nom du sociologue Abdelmalek Sayad et d'une rue au nom d'un habitant d'origine marocaine tué dans les années 1980. Ces mobilisations pour rendre visible la présence de l'immigration dans l'histoire de la commune donnent à voir les transformations de la configuration locale de l'action publique : elles témoignent des visées électoralistes des élus comme des ressources dont disposent au niveau local les militants associatifs et de quartier. L'inscription de l'«identité » de la commune dans l'histoire de l'immigration devient un enjeu pour une diversité d'acteurs engagés dans le jeu municipal.

La mobilisation de discours sur les cultures des immigrés revêt également une autre dimension : elle peut constituer une ressource discursive dans la définition des conflits, des rapports sociaux, de négociations diplomatiques. C'est ce que montre Rachida Brahim à travers la question du traitement des crimes racistes dans les années 1970. Reconstituant le travail de qualification de ces crimes par les agents de l'État chargés de les traiter (fonctionnaires des services de police, des ministères de l'Intérieur et des Affaires étrangères), sa contribution montre comment les violences policières et les meurtres de travailleurs immigrés sont rabattus sur l'instabilité psychologique ou l'inassimibilité supposées des victimes. Ce traitement s'inscrit plus généralement dans un cadrage discursif en termes de problèmes de «cohabitation culturelle ", alors que les conditions de l'immigration algérienne sont renégociées au niveau diplomatique. Ce sont ainsi les contours du statut de victime et le racisme qui sont redéfinis par ces acteurs.

Mais les agents de l'État n'ont pas le monopole de la définition du racisme. Comme le montre Laurence de Cock, cette définition est aussi le fait d'acteurs critiques des pouvoirs publics, en l'occurrence à travers la dénonciation du traitement du passé colonial dans les manuels scolaires. En revenant sur la mobilisation de l'Association pour la connaissance de l'Afrique contemporaine (ACHAC) pour la réforme des programmes d'enseignement de l'histoire, sa contribution replace ce discours critique dans une stratégie plus large d'imposition au sein du marché de l'édition des manuels d'histoire, du champ académique et auprès des pouvoirs publics. Les discours présupposant le transfert d'une «culture coloniale » sont appréhendés à l'aune du multipositionnement de l'ACHAC. L'article éclaire ainsi les conditions d'une définition contemporaines du racisme reposant sur l'idée d'un continuum entre le racisme subi par les colonisés et celui subi par les descendants d'immigrés, au prix d'une essentialisation de la figure de l'indigène et de la question immigrée. 
